\title{
Preparation and Application of a Novel, Environmental-Friendly Seed Coating Agent for Maize
}

\author{
Wenjin Wang, Defang Zeng \\ School of Resource and Environmental Engineering, Wuhan University of Technology, Wuhan, Hubei \\ 430070, China \\ Email: 18827071212@163.com
}

\begin{abstract}
An environmental-friendly seed coating agent for maize was mainly made up of natural polysaccharide polymer without pollution, and other additives. In order to clarify the effect of seed coating agent on maize yield, the effect on increasing yield was analyzed by the antibacterial test, the pest repellent experiment, the safety test and the field test with comparison of CK and after coating, which conducted by the e-feng brand corn seeds. With four major characteristics including antibiosis, desinsectization, increasing yield and environmental friendship, this seed coating agent is safer and more environmental-friendly than the traditional seed coating agent. The trial results from the laboratory and fields had shown that the anti-bacterial rate of this seed coating agent came to $90 \%$, and the anti-feeding rate of insect pests came to $81 \%$. After using this seed coating agent, the production of maize yield increased by $17.75 \%$ respectively, compared with untreated control. Besides, the $\mathrm{LD}_{50}$ of this seed coating agent was 10 times as much as traditional seed coating agent.
\end{abstract}

Keywords: Environmental-friendly seed coating agent, natural polysaccharide polymer, insect repellent, increasing yield

\section{Introduction}

In order to reduce the uses of pesticides and chemical fertilizers and to protect the environment, more attention is paid to the pesticides and fertilizers applied on the surface of crop seed, and it is urgent to come up to the novel seed coating agent (SCA) products and technologies. However, the traditional seed coating agents (TSCA) usually contain highly toxic pesticides (e.g. imidacloprid, carbofuran etc.) that are harmful to people, animals and the environment, and in turn will become serious threats to food safety and environment[1-2]. Therefore, how to prepare a novel environmental-friendly seed coating agent (ESCA) has become an important issue to be solved in the field of agriculture and environmental protection nowadays. After more than ten years of efforts, a kind of novel ESCA for maize has been prepared by us successfully. The main active component of the ESCA is a kind of natural polysaccharide polymer (NPP) extracted from the aquatic animal in deep sea without pollution. The ESCA can protect plants from insects mainly by inhibiting bacteria and expelling insects rather than sterilization or insecticide. The ESCA can also increase the maize yield by activating the enzyme activity in maize, and its increasing yield effect is obviously superior to poisonous TSCA. Therefore, it has five characteristics including antibiosis, insect repellent, enhancing stress resistance, increasing yield and environmental friendship.

\section{Experimental Procedure}

\subsection{Preparation of the ESCA for Maize}

First of all, the NPP is extracted from pollution-free aquatic in the deep sea according to the certain procedure. Secondly, this NPP is mixed and swelled with ion free water according to a certain proportion at room temperature for 2 hours, the certain amount of auxiliary reagent is added to this aqueous solution after they have dissolved completely. Afterwards, this liquid is stirred at $65^{\circ} \mathrm{C}$ and under $1.5 \mathrm{~atm}$ to be dissolved into a homogeneous solution. Other required components (such as: coalescent, plant growth regulators, anti-settling reagent, dispersants, pigments, etc.) are added to this homogeneous solution 
according to the certain proportion. Lastly, this solution is stirred sequentially at the temperature of $25^{\circ} \mathrm{C}$ for 4-5 hours until completely dissolved after the addition. After all these procedure, the ESCA for maize is prepared successfully.

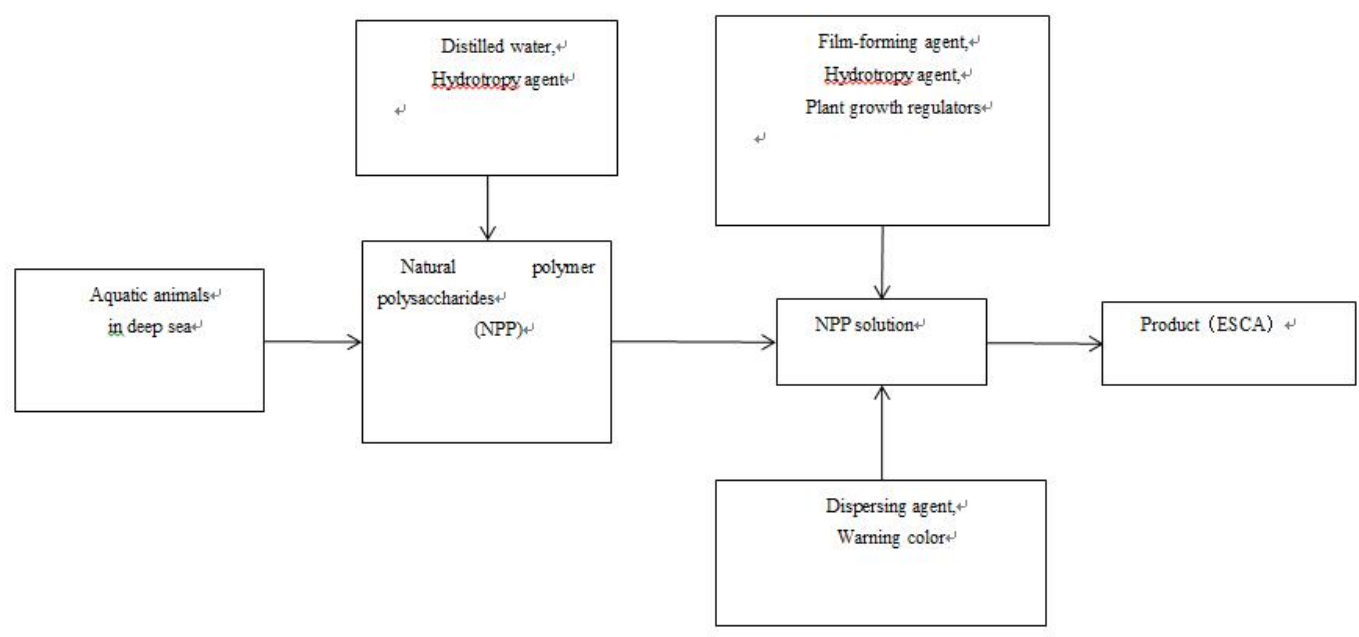

Figure 1. Preparation of ESCA process

\subsection{Experiment of the Bacteriostatic Effect of ESCA}

In this experiment, Sphacelotheca reiliana (Kuhn) Clint, sheath blight fungus, Setosphaeria turcica were served as the main objects so as to test inhibitory effect on pathogens between the ESCA and TSCA. The method of "indoor growth rate measurement of maize" [3-6] was used to study the bacteriostatic action on pathogens between two groups (Zhao Bin et al. 2002). Inhibition rate calculation formula was as follows (Qin Cuili et al. 2008, Ning Hailu et al. 2005 , G. F. Burkhanova L. G. et al. 2007):

$$
I=\frac{B-T}{B} \times 100
$$

I-Bacteriostatic rate(\%);

B - Diameter of the untreated bacterial colony $(\mathrm{mm})$;

$\mathrm{T}$-Diameter of the treated bacterial colony $(\mathrm{mm})$.

\subsection{Experiment of the Repellent Effect of the ESCA on Pests}

In this experiment, the cutworms were served as the research object, and "guidelines for the determination of pesticides in laboratory" and "artificial feed-mixing drug method" [7-8] were used to examine the ESCA on cutworms anti-feeding effect. Anti-feeding rate calculation formula is as following: (China agricultural standard, 1154.6-2006 NY/T, Abul Hussamet et al. 2007):

$\mathrm{N}$-Antifeedant rate $(\%)$;

$$
N=\frac{C-T}{C} \times 100
$$

C-Food consumption for untreated control $\operatorname{group}(\mathrm{g})$;

$\mathrm{T}$-Food consumption for treated $\operatorname{group}(\mathrm{g})$.

\subsection{The Test of the ESCA's Effect on the Maize Increasing Yield}

The same kind of maize seed was respectively coated with the ESCA and TSCA for maize. The uncoated maize seed was set as CK to conduct field trial with both maize seed coating simultaneously. That is to say that the tests were carried out at the same conditions and measured by the maize yield. It shows that the SCA's effect on increasing yield and the difference on maize yield between the two kinds of SCAs. Methods and procedures of maize field trials were conducted in accordance with national standards GB/T 
17980.139-2004.

\subsection{The Experiment on Comparison of the Toxicity and Safety of the SCAs}

In accordance with toxicology test methods in pesticide registration[9] (China National Standards: GB15670-1995), Kärber Method was used in the experiment on comparison of the toxicity and safety of the ESCA and TSCA (Carbofuran, Imidacloprid) for maize. It was carried out respectively with rats as the test subjects under identical experimental conditions. The toxicity and safety of the SCAs were determined by the median lethal dose LD50 in rats of each SCA. The LD50 calculation formula is as following:

$$
L D_{50}=\log ^{-1}\left[X m-i\left(\sum P-0.5\right)\right]
$$

Xm - The dose's logarithm of maximum dose group;

$\mathrm{i}$ - The logarithm of the ratio of high dose and low dose for two adjacent groups(the difference between logarithmic dose of two adjacent groups);

$\mathrm{P}$ - Animals' mortality in each group are expressed in decimal places(if the mortality rate was $80 \%$,it should be written 0.80 );

$\sum \mathrm{P}$ - The sum of the mortality of the animals for each group;

$\mathrm{n}$ - The number of animals in each group.

\section{$3 \quad$ Results and Analysis}

\subsection{Comparison of Different SCA's Bacteriostatic Effect}

Comparative test of different SCA's bacteriostatic effects are shown in Table 1.

Table 1. Effects of different SCAs on bacteriostasis

\begin{tabular}{llll}
\hline SCAs & $\begin{array}{l}\text { Head smut fungus } \\
\text { bacteriostatic rate }(\%)\end{array}$ & $\begin{array}{l}\text { Rhizoctonia solani } \\
\text { bacteriostatic rate }(\%)\end{array}$ & $\begin{array}{c}\text { Setosphaeria turcica } \\
\text { bacteriostatic rate (\%) }\end{array}$ \\
\hline ESCA & $93.72 \pm 1.4 \mathrm{a}$ & $88.96 \pm 1.1 \mathrm{ab}$ & $87.82 \pm 1.3 \mathrm{a}$ \\
Carbofuran & $90.05 \pm 1.3 \mathrm{ab}$ & $85.21 \pm 0.9 \mathrm{a}$ & $84.36 \pm 0.9 \mathrm{~b}$ \\
Imidacloprid & $89.95 \pm 1.7 \mathrm{~b}$ & $84.38 \pm 1.4 \mathrm{~b}$ & $83.57 \pm 1.0 \mathrm{c}$ \\
\hline
\end{tabular}

NOTE: The data in the table is average value \pm standard deviations. The lowercase letters in the same column indicate significant differences between the treatments at the 0.05 level. The same capitalization of the same column indicates a significant difference between the different treatments at the 0.01 level.

As is showed in Table1, the ESCA was significant inhibition on common germs (head smut fungus, Rhizoctonia solani, Setosphaeria turcica etc.) during the period of maize's growth. The average bacteriostatic rate, which could reach $90.17 \%$, is 3 percentage points higher than the TSCA which is invented by Gao (Gao Youjun et al. 2015).[10] So the ESCA can effectively inhibit or reduce the incidence of major diseases during the period of maize's growth and make maize be able to thrive safely, so as to make great contributions to the maize yield.

\subsection{The Results of Repellent Effect on Pests and Diseases of the ESCA}

The results of repellent effect on pests and diseases of the ESCA are shown in Table 2 
Table 2.The repellent effect results on pests and diseases of the ESCA

\begin{tabular}{|c|c|c|c|c|c|}
\hline $\begin{array}{l}\text { Concentration of ESCA coated } \\
\text { on artificial feed }(\mathrm{mg} / 100 \mathrm{~g})\end{array}$ & $\begin{array}{l}\text { Number } \\
\text { of pests }\end{array}$ & $\begin{array}{l}\text { Artificial feed } \\
\text { weight }(\mathrm{g})\end{array}$ & $\begin{array}{l}\text { Material weight } \\
\text { after } 48 \mathrm{~h}(\mathrm{~g})\end{array}$ & $\begin{array}{l}\text { Antifeedant } \\
\text { rate }(\%)\end{array}$ & Average \\
\hline \multirow{4}{*}{13} & \multirow{4}{*}{24} & 5.25 & 4.77 & 78.28 & \multirow{4}{*}{$81.29 \%$} \\
\hline & & 6. 92 & 6.55 & 83.41 & \\
\hline & & 5. 49 & 5.08 & 82.33 & \\
\hline & & 5.84 & 5. 41 & 81. 14 & \\
\hline \multirow{4}{*}{10} & \multirow{4}{*}{24} & 5.87 & 5.07 & 63.80 & \multirow{4}{*}{$63.40 \%$} \\
\hline & & 5.36 & 4.58 & 65.02 & \\
\hline & & 6.05 & 5.20 & 63.36 & \\
\hline & & 5.18 & 4.30 & 61.40 & \\
\hline \multirow{4}{*}{7} & \multirow{4}{*}{24} & 4.96 & 3.91 & 52.49 & \multirow{4}{*}{$50.88 \%$} \\
\hline & & 5.75 & 4.61 & 48.88 & \\
\hline & & 5.34 & 4.25 & 53.02 & \\
\hline & & 5.88 & 4.72 & 49.12 & \\
\hline \multirow{4}{*}{0} & \multirow{4}{*}{24} & 5.36 & 3.15 & \multirow{4}{*}{$\begin{array}{l}\bar{u} \\
\square\end{array}$} & \\
\hline & & 6. 23 & 4 & & \\
\hline & & 6.55 & 4. 21 & & \\
\hline & & 5.94 & 3. 66 & & \\
\hline
\end{tabular}

Note: After $48 \mathrm{~h}$, experiments on insect mortality rate was 0 , so that the experimental data is valid.

Compared with the CK, the ESCA with different weight was coated on artificial feed per $100 \mathrm{~g}$, so as to explore the antifeedant effect of different weight of ESCA. The results were shown in Table 2. As can be seen from the experimental results, the higher the concentration, the more obvious antifeedant effect. When the concentration of ESCA was $13 \mathrm{mg} / 100 \mathrm{~g}$, antifeedant rate of the black cutworm was $81.29 \%$ on average. These results indicate that the ESCA has obvious antifeedant effect on pest.

Repellent effects of the ESCA on the pest are shown in Figure 2. A comparison of the antifeedant effect of the seed coating agent was made at Shandong Agricultural University, P.R.China.

As can be showed from Figure 2, tablets coated with the ESCA(left) had less consumption. The experiment showed that ESCA had obvious antifeedant effect on crop pests. The ESCA not only protects the biodiversity, but also protects the crops from the pest invasion, which has the important environmental protection significance.

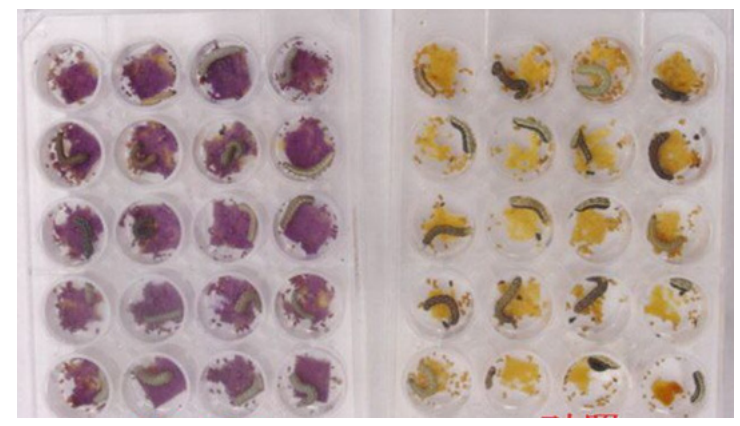

Effect of ESCA on pest antifeedant (left); Effect of CK on pest antifeedant (right).

Figure 2. Comparison chart of the ESCA's antifeedant effect on pest cutworms

\subsection{The Field Test Results for Increasing Yield Rate of the SCAs}

The field test results of the SCAs are shown in Table 3. 
Table 3. The field test results of the SCAs

\begin{tabular}{lllllll}
\hline $\begin{array}{l}\text { Treated } \\
\text { Group }\end{array}$ & $\begin{array}{l}\text { Germination } \\
\text { rate }(\%)\end{array}$ & $\begin{array}{l}\text { Ear row } \\
\text { number }\end{array}$ & $\begin{array}{l}\text { grain } \\
\text { number }\end{array}$ & $\begin{array}{l}\text { 1000- grain } \\
\text { weight }\end{array}$ & $\begin{array}{l}\text { Maize Yield } \\
(\mathrm{Kg} / \mathrm{ha})\end{array}$ & $\begin{array}{l}\text { Growth } \\
\text { rate }(\%)\end{array}$ \\
\hline ESCA1: 50 & $86.25 \mathrm{Aa}$ & $13.80 \mathrm{Aa}$ & $31.13 \mathrm{Aab}$ & $321.98 \mathrm{ABa}$ & $8461.20 \mathrm{ABab}$ & 11.47 \\
ESCA1:40 & $88.13 \mathrm{Aa}$ & $13.90 \mathrm{Aa}$ & $31.50 \mathrm{Aa}$ & $323.00 \mathrm{Aa}$ & $8786.25 \mathrm{Aa}$ & 15.75 \\
ESCA1:30 & $87.50 \mathrm{Aa}$ & $13.85 \mathrm{Aa}$ & $30.18 \mathrm{ABbc}$ & $321.47 \mathrm{ABa}$ & $8458.73 \mathrm{ABab}$ & 11.43 \\
TSCA1:40 & $81.25 \mathrm{Aa}$ & $13.60 \mathrm{Aa}$ & $29.35 \mathrm{BCcd}$ & $322.05 \mathrm{Aa}$ & $8213.70 \mathrm{Bb}$ & 8.21 \\
CK & $81.88 \mathrm{Aa}$ & $13.90 \mathrm{Aa}$ & $28.50 \mathrm{Cd}$ & $312.75 \mathrm{Bb}$ & $7590.83 \mathrm{Cc}$ & \\
\hline
\end{tabular}

As can be showed from Table 3, when the seed ratio of ESCA is 1: 40, the germination rate, ear row number, grain number, 1000-grain weight and yield per unit area were higher than the TSCA group and CK group. And the yield was improved by $15.75 \%$ compared with the CK group, which was higher than the SCA prepared by Gao Youjun (Gao Youjun et al. 2014)[11]. As a result, the field trial results indicate that the ESCA can obviously increase maize yield.

\subsection{Results of SCAs' Toxicity $\mathrm{LD}_{50}$}

Table 4. $\mathrm{LD}_{50}$ of SCAs

\begin{tabular}{|c|c|c|c|}
\hline $\mathrm{SCA}$ & $3 \%$ Carbofura & Imidacloprid & ESCA \\
\hline $\mathrm{LD}_{50}(\mathrm{mg} / \mathrm{kg})$ & 437 & 450 & 5321 \\
\hline Level of material toxicity & Moderate toxicity (50-500) & Moderate toxicity (50-500) & Low toxicity $(>2000)$ \\
\hline
\end{tabular}

As can be showed from Table 4, the toxicity LD50 of TSCAs (carbofuran, imidacloprid) is in the range of moderate toxicity from 437 to $450 \mathrm{mg} / \mathrm{kg}$, which does greater harm to the environment, human and animals. However, the toxicity LD50 of ESCA is in the range of low toxicity for $5321 \mathrm{mg} / \mathrm{kg}$, which is lower than salt. Therefore, ESCA has the characteristics of safety and environmental protection.

\section{$4 \quad$ Yield Increase Effectiveness Analysis of ESCA}

\subsection{ESCA Has a Good Antibacterial Effect to Achieve Increased Production}

As a cationic type of biological coagulation agent, NPP can be copolymerized and flocculated with bacteria and form a dense polymer film on the surface of the cell, which has great influences on the cell membrane's permeability and the metabolism of the whole cell. As a kind of cationic electrolyte, NPP can use its biological compatibility to enter the bacterial cells through the cell membrane and combine with negatively charged substances (such as nucleic acids and proteins, etc.) in cells, which inhibits replication of DNA and synthesis of protein, hinders the normal cellular physiology function of pathogenic bacteria, leads to a serious disorder to the new metabolism of plant pathogenic bacteria, and prevents the normal growth of plant pathogenic bacteria, so as to achieve the antibacterial effect[12-16].

\subsection{ESCA Has a Good Insect Repellent Effect to Achieve Increased Production}

The main active ingredients NPP in the ESCA bring stimulation or inhibition to the receptor of common crop pests, causing the pests' action of antifeedant. NPP in the ESCA can influence and change the feeding behaviour of the insect by changing the intestinal amylase, protease and lipase activity. If insects feed on antifeedant substance, metabolism will be disordered. In addition, the seeds coated by the ESCA can produce some systemic antibody which plays a certain role in repellenting the pests in the soil by the whole 
plants' resistance with its own absorption and conduction, which fundamentally prevents the plants from pest invasion.

\subsection{The Active Ingredient of ESCA Has Biological Efficacy to Achieve Increased Production}

The NPP, which is the main component of the ESCA, can be used as a kind of new plant growth regulator, and it is useful to promote seed germination and crop increase yield (Ziani K, Gao Wei 2010, Zhou Tian et al. 2003, Chen et al. 2005, Xue Qihan et al. 1999). The free amino of NPP chains can chelate with trace elements in the soil, which is more conducive to crop absorption of these trace elements, so the root activity of crop is greatly improved and developed root system. At the same time, the NPP molecules have good film-forming, hydrophilic and porous permeability, which is conducive to inhalation of nutrients to reduce the loss of nutrients ,to accelerate the exclusion of metabolites and improve emergence rates , thus laying the foundation for improved crop yields. ${ }^{[17-21]}$

\subsection{ESCA Enhances the Photosynthesis by Increasing the Chlorophyll Content to Achieve Increased Production}

NPP contains a large number of free amino, which promotes the synthesis of chlorophyll in plants, thereby enhancing chlorophyll's content. ${ }^{[22]}$ The increasing of chlorophyll's content not only accelerates endosperm starch hydrolysis in the process of seed germination, but also provides adequate nutrients and carbon source for the seed germination and crop yield. Besides, it can increase the photosynthesis of crops and promote the increasing of organic matter in crops, thus it plays a very important role in promoting the photosynthesis and increasing yield under drought stress conditions.

\section{Conclusion}

As demonstrated in this study, this kind of novel environmentally friendly seed coating agent was prepared using polysaccharide as the main material, which played a positive role in yield increment and pest control through enhancing seed vigor. The results show that the output of maize seeds coated with this novel agricultural agent was increased by $17.75 \%$, the anti-bacterial rate of this seed coating agent came to $90 \%$, which was higher than the traditional seed coating agent, and the anti-feeding rate of insect pests came to $81 \%$ compared with CK group.

Acknowledgements. We are deeply grateful to Wuhan Science and Technology Bureau of China for financial support (No.201120922303). A special acknowledgement should give to Wuhan University of Technology for its experimental conditions and technical support.

\section{References}

1. Feng Jianguo, Zhang Xiaojun, Yu Chi et al. Research on the application of pesticide formulations in China Journal [J].China Agricultural University, 2013,18(2): 220-225.

2. Ji Qingxun, Han song, Wang Juan. Wheat, maize seed coating agent side effects [J]. China Pesticide magazine, 2013, 52 (12): 865-870

3. Zhao Bin, He Shaojiang, Microbiology experiment [M]. Beijing: Science and Technology Press, 2002 .

4. Qin Cuili, [ed] Li Songbiao. Microbiology experimental technique [M]. Beijing: China Ordnance Industry Press, 2008.

5. Ning Hailu, Rui Fuxu, Wu Limin, Zhang Dingfa. Different culture medium of Rhizoctonia cerealis growth reproduction and virulence [J]. Chinese Agricultural Science Bulletin, Chinese Agricultural Science Bulletin, 2005, 21 (2): 262-263.

6. G. F. Burkhanova L. G. Yarullina, and I. V. Maksimov. The Control of Wheat Defense Responses during Infection with Bipolaris sorokiniana by Chitooligosaccharides[J]. Russian Journal of Plant Physiology 2007,54, (1): 104-110.

7. China agricultural standard, 1154.6-2006 NY/T, sixth part of the standard for indoor bioassay of pesticide.

8. Abul Hussam, Dongmei Cheng, Xu Hanhong et al. Insect antifeedant concentration and suppression of food 
concentration of basic statistical analysis [J]. China Guangdong Agricultural Sciences, 2007, (4): 62-64.

9. China National Standards: GB15670-1995, a method for the testing of pesticide registration toxicology.

10. Gao Youjun, Wang Hongke, Liu Wanlin. A preparation method of suspended seed coating agent on preventing smut in the corns: China, 201410565336.2[P].2015.01.07.

11. Gao Youjun, Wang Hongke, Liu Wanlin. A preparation method of suspended seed coating agent on preventing smut in the corns: China, 201410565336.2[P].2015.01.07.

12. Gan Guoying, Pu AURI, Zhang Xin, et al. Chitosan inhibiting mechanism research progress of plant diseases [J]. China Guangxi Agricultural Sciences, 2009, 40(6):669-674.

13. Chen Xiguang, Liu Nan, Liu Chengsheng, et al. Research progress on the antibacterial properties of chitosan [J]. China Marine Science, 2005, 29 (10):90-92.

14. Tong Youcai. Maize efficiency planting. Beijing:China Agricultural Press, 2005:205.

15. Ying Chien Chung, Chih Yu Chen. Antibacterial characteristics and activity of acid-soluble chitosan[J]. Bioresource Technology , 2008, 9 (11): 2806-2814.

16. K Ziani, Ms fern ndez ndez-Pan, royo m, et al. Antifungal activity of LMS and solutions based on chitosan against typical seed fungi[J]. Food Hydrocolloids, 2009 (23): 2309-2314.

17. Ziani K, Urs a B Mat case, J I. Ap.

18. Gao Wei. Application of Chitin and Chitosan in Agriculture [J]. Agriculture and technology, 2010, 29 (8):84-85.

19. Zhou Tian,Liu Jing, Zhou Xiaomei, et al. Physiological effects of chitosan and its effect on crop yield[J]. Jilin Normal University (Natural Science), 2003, 24 (2): 18-21.

20. Chen, Xu L. Chitosan regulation of plant growth and development and inducing plant resistance research progress [J]. Yunnan plant research, 2005, 27 (6): 613-619.

21. Xue Qihan, Shi Suyun, Liu Aimin, et al. Effect of Chitosan on the growth of maize [J]. natural products research and development, 1999,11 (2): 32-35.

22. Wang Guowu, Han Xiaodi. Chitosan on Seed Germination of several cruciferous vegetables [J]. Seeds, 2010, 29 (8):99-101.

\section{Appendix}

Comparison table of full name and abbreviation

\begin{tabular}{ll}
\hline full name & abbreviation \\
\hline seed coating agent & SCA \\
traditional seed coating agents & TSCA \\
environmental-friendly seed coating agent & ESCA \\
natural polysaccharide polymer & NPP \\
untreated control & CK \\
\hline
\end{tabular}

